\title{
Surface Micromachined Magnetic Actuators
}

\author{
Chang Liu, Tom Tsao, Yu-Chong Tai and Chih-Ming Ho* \\ Electrical Engineering 116-81, California Institute of Technology \\ Pasadena, CA 91125, USA \\ *MANE, The University of California at Los Angeles \\ Los Angeles, CA 90024, USA
}

\begin{abstract}
A surface micromachined micro magnetic actuator(also called a magnetic flap) as an integrated part of an active micro electro-mechanical fluid control system is described here. The flaps are fabricated by surface micromachining technology and are capable of achieving large deflections(above $100 \mu \mathrm{m}$ ) with magnetic forces in stationary air. Special microfabrication issues involved in fabricating magnetic flaps with large areas are discussed. Mechanical characterizations of the flaps, including the intrinsic stresses of thin film materials and frequency response, are presented. Thermal actuation is capable of producing large flap displacements and has been theoretically and experimentally studied.
\end{abstract}

\section{INTRODUCTION}

Magnetic actuation, compared with electrostatic driving mechanisms, can have the advantage of providing stronger forces over a longer distance[1,2]. Electromagnetic driving can be utilized in many different configurations [3,4], even in combination with electrostatic forces[5]. The introduction of electrochemical deposition of permalloy (e.g. 50/50 FeNi) has dramatically increased the power of electro-magnetic driving and the efficiency of magnetic actuators $[6,7,8,9]$. Here, we emphasize the study of the magnetic actuation using a surface micromachined moving coil.

Figure 1 shows the perspective and cross-sectional view of a typical magnetic flap, which consists of a magnetic coil located on top of a flap hinged by two cantilever beams on one side. Our surface micromachined magnetic actuator serves as an integral part of a MEMS system to control turbulence for drag reduction. In an ongoing University Research Initiative(URI) project, an array of shear stress sensors senses local vortices in a turbulent flow, an on-chip neural network processes the sensor signals according to its built-in algorithm, and the output signals drive a micro magnetic-flap array to reduce the vortices. The flaps are required to achieve vertical deflection of at least $\pm 100 \mu \mathrm{m}$ at the end point, have a bandwidth over $10 \mathrm{kHz}$, and provide forces on the order of 1-10 $\mu \mathrm{N}$. Among all the possible mechanisms, electromagnetic actuation is chosen here for this application. The fact that a magnetic actuator can be fabricated in a microelectronics compatible process also makes it an reasonable choice for MEMS.

\section{DESIGN}

As shown in Fig. 1, the magnetic coil is located on top of a laminated thin film plate, which is supported by either two cantilever beams at one end or four serpentine beams at the four corners. Sizes of the flaps vary from $250 \mu \mathrm{m}$ to $900 \mu \mathrm{m}$ on the side, the lengths of the beam vary from 100 to $360 \mu \mathrm{m}$ and the beam widths range from 14 to $50 \mu \mathrm{m}$. Etch holes (typically $15 \times 15 \mu \mathrm{m}^{2}$ ) were strategically placed in the plate to allow faster etching of the PSG sacrificial layer and to ensure that all structures were released in roughly the same amount of time. The fluid control aspects of those etching holes in the flow field are under study.

There are four facets to the design issues: magnetic, mechanical, thermal and electrical. The fluid dynamic aspect of the design is also very important, however it is beyond the scope of this paper. The magnetic force that the flap experiences in a magnetic field with a gradient is generally governed by $[10]$

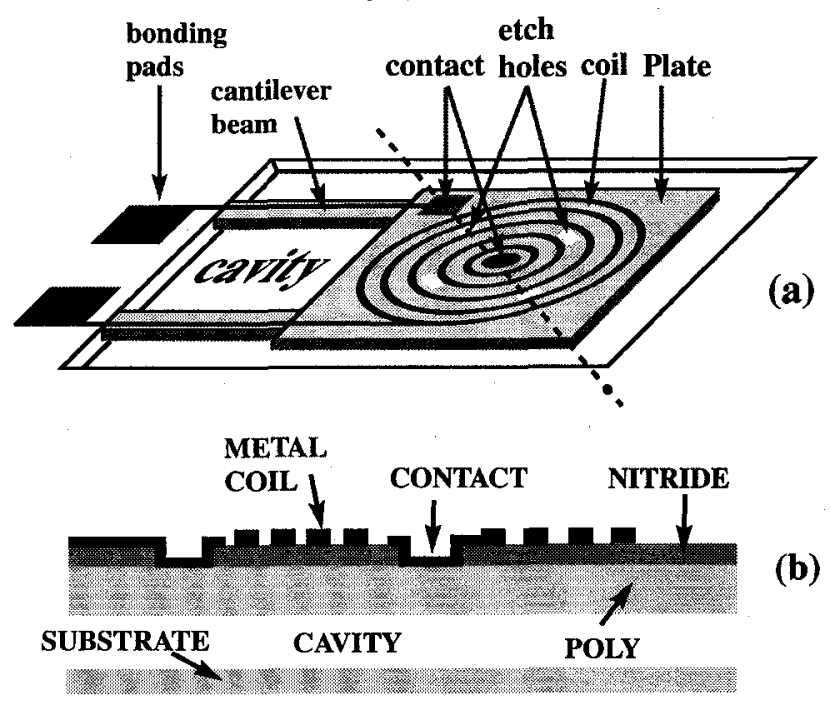

Fig. 1: (a) perspective view of a magnetic flap; (b) cross-sectional view of the plate along the dotted line in (a) showing the layered structures: the plate is composed of polysilicon, silicon nitride and a metal coil. Polysilicon forms the return path for the current loop. 


$$
F=(\vec{m} \cdot \vec{\nabla}) \vec{B}
$$

where $\vec{m}$ is the magnetic moment and $\vec{B}$ is the magnetic flux density. In the case of a current-carrying coil,

$$
\vec{m} \cong N I \pi\left(R_{a v}\right)^{2} \vec{n}
$$

where $N$ is the number of turns of the coil; I is the current that passes through the coil, $R_{a v}$ is the average radius of the coils and $\vec{n}$ is normal vector of the current loop.

Mechanically, the choice of the spring constant of the flap must be a compromise. In order to achieve large displacements, the flap should have a small spring constant. However, having a large bandwidth requires a large spring constant. The force constant of the flap can be obtained by using an approximate composite-layer model[11] or by more precise method such as finite element simulation. In the current design, all our flaps are designed to have force constants in the range of 0.001 $0.01 \mathrm{~N} / \mathrm{m}$.

The intrinsic stresses of the different layers contribute to a bending moment acting on the plate, which results in the plate having a curved, rather than flat, shape at rest. The magnitude of the curvature of a thin bi-material plate can be calculated using[12]

$$
\frac{F h}{2}=\frac{E_{1} I_{1}+E_{2} I_{2}}{\rho}
$$

where $\mathrm{F}$ is the lateral force due to the intrinsic stress, $\mathrm{h}$ is the total height of the bi-material layer, $E_{1}$ and $I_{1}$ are the Young's Modulus and moment of inertia of the top layer, $E_{2}$ and $I_{2}$ are the Young's Modulus and moment of inertia of the bottom layer, and $\rho$ is the radius of curvature of the plate.

Thermally, as the temperature of the flap rises, the thermal mismatch of different materials in the composite layers will cause the flap to bend down, which is not desirable in our current project. Given the geometry and material composition, this bending can be calculated[12]. On the other hand, this effect has been used by several authors to make thermal actuators in the past $[13,14]$. In making the prototype device, we did not seek to specifically solve the thermal problem; but this thermal effect is thoroughly studied and we intend to minimize thermal bending in our next generation of devices.

Electrically, low resistance is desirable to minimize heat generation and thus thermal bending of the flap. The total resistance is composed of the metal coil resistance, the contact resistance between metal and doped polysilicon, and the resistance of the polysilicon plate. The polysilicon plate resistance contributes the most(60$70 \%$ ) to the total resistance (ranging from 30 to $70 \Omega$ ) and the heating.

\section{FABRICATION}

The fabrication process is briefly described in Fig. 2. A thick $(2.5 \mu \mathrm{m})$ phosphosilicate glass (PSG) sacrificial layer with a measured $6 \%$ phosphorous content is first de- posited on the wafer surface using low pressure chemical vapor deposition(LPCVD), followed by a $6000 \AA$ thick LPCVD polysilicon deposition at $620^{\circ} \mathrm{C}$. In order to dope the polysilicon layer, the wafer is coated with another $5000 \AA$ of PSG and then annealed at $950^{\circ} \mathrm{C}$ for one hour to release its intrinsic stress[15]. During the annealing the polysilicon is doped by phosphorus diffusion and the resulting sheet resistivity is measured as $50.5 \Omega / \square$. The top PSG is subsequently removed and the polysilicon patterned by photolithography. We deposited a layer of $3000 \AA$ LPCVD low stress silicon nitride at $820^{\circ} \mathrm{C}\left(\mathrm{SiH}_{2} \mathrm{Cl}_{2} / \mathrm{NH}_{3}\right.$ ratio being 4$)$ to cover the poly plate for insulation and then pattern the nitride to have contact holes.

At first we attempted to use $\mathrm{Al}$ as the metalization, in which case approximately $4000 \AA$ aluminum layer is evaporated and patterned to form the coils We then used buffered hydrofluoric acid (BHF) and oxide pad etchant[16] to etch the sacrificial layer. However, in order to completely underetch a $200 \times 200 \mu \mathrm{m}^{2}$ plate size, it took the pad etchant approximately 3 hours and BHF 30 minutes. The slow etch rate, together with low etching selectivity over Al metalization, making the yield unacceptable $(\sim 10 \%)$.

$\mathrm{Cr} / \mathrm{Au}$ metalization is then sought because of its chemical stability in HF. An $100 \AA$ chromium layer (for adhesion promotion) and a $4000 \AA$ gold layer form the metalization. It is found that $49 \% \mathrm{HF}$ can be used to completely undercut the plate structure without damaging the metalization; the etching process takes about 2 minutes to complete and the etching on the plate materials(nitride and polysilicon) is minimal.

The subsequent drying process is also essential for obtaining a high yield, and several authors have reported on different drying techniques $[17,18,19,20]$. Our standardized process includes rinsing the wafer in de-ionized water for 20 minutes, and in acetone and then in alcohol for 1 minute each. After alcohol removal by 10 minutes DI

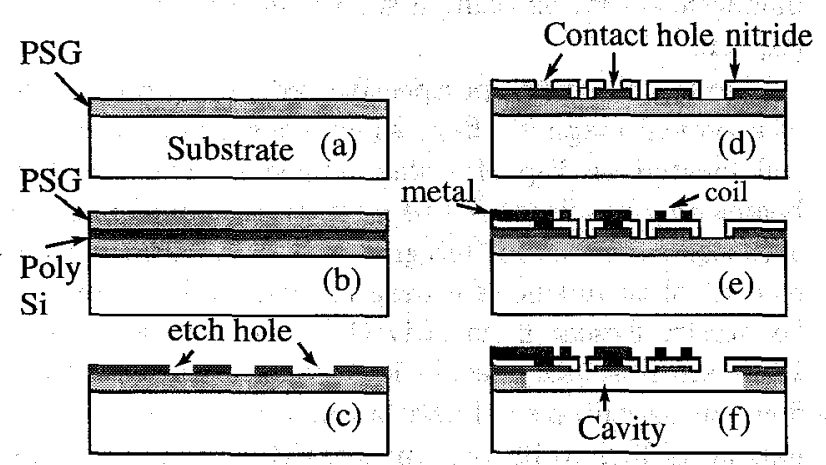

Fig. 2: Process flow of thin film magnetic actuator. (a) PSG sacrificial layer deposition; (b) polysilicon and PSG deposition, with polysilicon doped by thermal annealing;(c) polysilicon patterning to form etching holes;(d) nitride deposition and patterning to have contact holes; (e) metalization and patterning to forms magnetic coil;(f) sacrificial layer etching and tlap release. 
water rinse, the wafer is baked dry by an infrared lamp. The flap stiction to the substrate is almost negligible and a high yield near $100 \%$ was obtained. We found that infrared lamp baking can be used in conjunction with convection oven baking at $120^{\circ} \mathrm{C}$. Some finished flaps are shown in figure 3 and 4 and the details of etch holes are shown in Fig. 5.

In order to prevent the flap from sagging down to the substrate and thus forming permanent bond during fabrication, silicon nitride tethers are used to hold the plate in place during sacrificial etching process. In the current process, the tethers are typically $100 \mu \mathrm{m}$ long, 6 $\mu \mathrm{m}$ wide and $3000 \AA$ thick(same as the low stress nitride layer thickness); they are manually broken by manipulator probes once the plates are freed. Since manual tether breaking could become tedious and inefficient when the actuator array is large, photoresist tethers of the same dimension have also been tested so they can be removed by oxygen plasma ashing after the plates are freed and dried. However, the photoresist tethers were not able to withstand the $49 \%$ HF etching process and most of them peel off within 2 minutes of staying in HF. We are looking for alternatives to replace the silicon nitride tethers with other plate supporting structures that can be plasma removed.

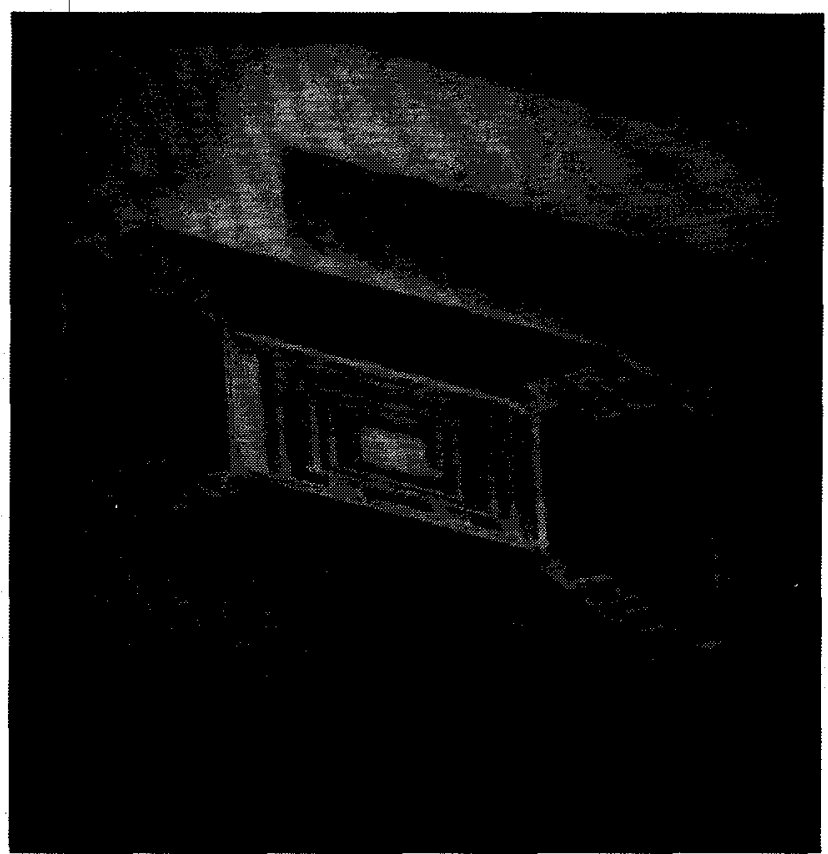

Fig. 3: An SEM picture of a magnetic actuator supported by four serpentine beams at corners. The plate is $250 \times 250 \mu \mathrm{m}^{2}$, the beams are $250 \mu \mathrm{m}$ long and $15 \mu \mathrm{m}$ wide, and the plate is made of a polysilicon/nitride composite layer approximately $9000 \AA$ in thickness.

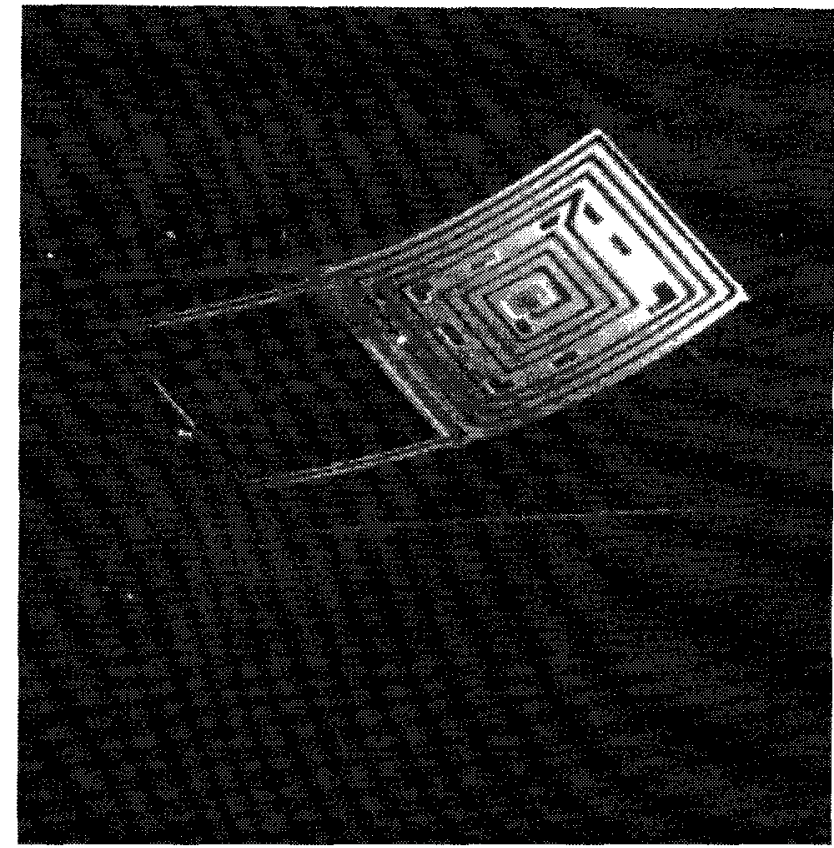

Fig. 4: An SEM picture of a magnetic flap suspended by two cantilever beams at one end. The plate size is $300 \times 300 \mu \mathrm{m}^{2}$, the beam is $200 \mu \mathrm{m}$ long and $24 \mu \mathrm{m}$ wide, and the plate is about $9000 \AA$ in thickness. The flap is curved due to combined intrinsic stress of nitride, polysilicon and metal.

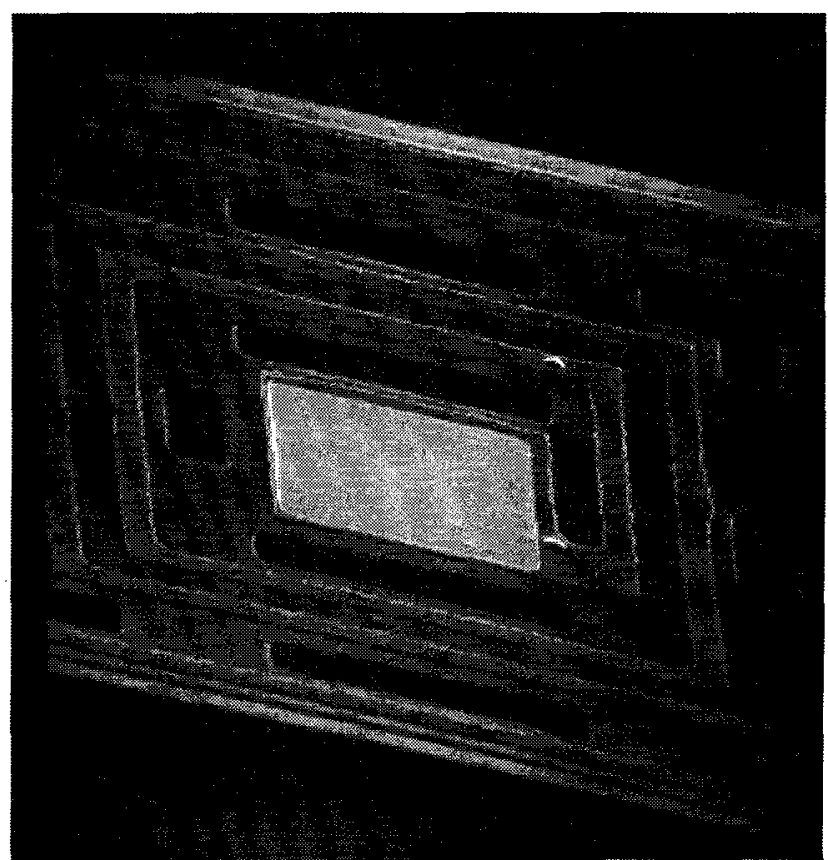

Fig. 5: An SEM close-up view of the magnetic flap illustrating the strategic location of etching holes on the plate. 


\section{TESTING RESULTS}

By using the setup shown in Fig. 6, the full motion of the magnetic flap is video-recorded from its side and used later for detailed analysis.

\section{Intrinsic stress}

The intrinsic flap bending is measured by a microscope and some typical vertical deflections at the end of the flaps are listed in Table 1. By comparing the magnitude of deflection of several flaps before and after metalization(both $\mathrm{Al}$ and $\mathrm{Au}$ ) removal, almost no difference was detected; it seems that the metalization does not

contribute significantly to the intrinsic bending. We can thus use a simple model of $3000 \AA$ thick silicon nitride on top of $6000 \AA$ thick polysilicon to calculate the radius of curvature. The low stress nitride has a tensile stress on the order of $150 \mathrm{MPa}[21]$; the polysilicon stress is much less predictable and the stress could change from tensile to compressive for different wafers along the boat. It has been found that polysilicon deposited under similar conditions as ours was can have a stress very close to zero[22]. If we assume that the metal has a negligible affect on the stress and that the plate bending is much larger than the beam bending, we can get an estimate of the bending due to intrinsic stress by Eq.3. Using the Young's modulus of $300 \mathrm{GPa}$ for silicon nitride and 150 $\mathrm{GPa}$ for polysilicon, and assuming zero intrinsic stress for polysilicon, we obtained a $\rho$ of roughly $600 \mu \mathrm{m}$ for a $860 \times 430 \mu \mathrm{m}^{2}$ plate. This agrees well with the measured value of the radius of curvature for this plate, which is on the order of $700 \mu \mathrm{m}$.

When $\mathrm{Al}$ was used as metalization, we found that the intrinsic bending for a given device increased by about $25 \%$ when the devices are further annealed at $400{ }^{\circ} \mathrm{C}$ (in an effort to reduce the Al-polysilicon contact resistance) This observation implies that annealing can significantly increase $\mathrm{Al}$ stress, a result which agrees well with previous studies on Al stresses[23].

\section{Thermal motion}

The thermal effect can contribute to a significant deflection of the flap if a large power(e.g above $10 \mathrm{~mW}$ ) is applied. Horizontal and vertical deflections of more than $100 \mu \mathrm{m}$ have been observed in almost all devices. In one thermal actuation test for a flap $860 \times 350 \mu \mathrm{m}^{2}$, the side profiles of the flap before and after applying coil current were captured by video and shown in Fig. 7. The magnitude of the thermal bending is comparable with previously published data[13].

If we consider our plate to essentially be a bi-layer thermostat composed of a gold layer and a composite nitride/poly layer, we can use the standard thermostat equation [12] to obtain an estimate of the temperature. We combine the poly and nitride into one layer because the thermal coefficients of expansion and Young's moduli of poly and nitride are relatively close compared with

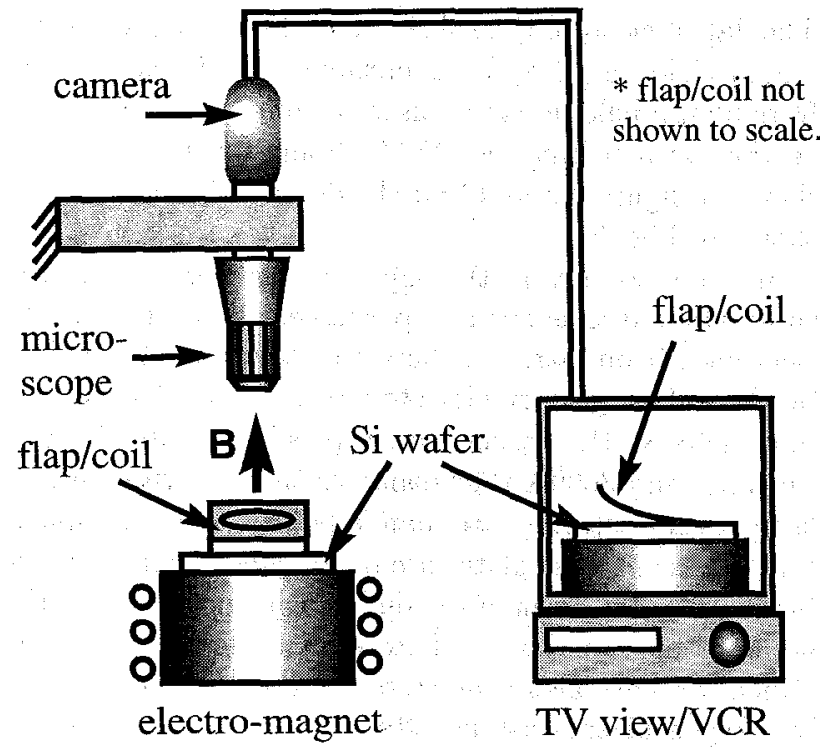

Fig.6: Experimental setup for studying the motion of magnetic flap. The microscope is placed on the side of the flap to record flap motion profile during thermal and magnetic actuations.

\begin{tabular}{|c|c|c|c|c|}
\hline $\begin{array}{c}\text { flap } \\
\text { length } \\
(\mu \mathrm{m})\end{array}$ & $\begin{array}{c}\text { flap } \\
\text { width } \\
(\mu \mathrm{m})\end{array}$ & $\begin{array}{c}\text { beam } \\
\text { length } \\
(\mu \mathrm{m})\end{array}$ & $\begin{array}{c}\text { beam } \\
\text { width } \\
(\mu \mathrm{m})\end{array}$ & $\begin{array}{c}\text { max. } \\
\text { deflection } \\
(\mu \mathrm{m})\end{array}$ \\
\hline \hline 200 & 200 & 100 & 14 & 75 \\
\hline 300 & 300 & 200 & 18 & 160 \\
\hline 400 & 350 & 200 & 14 & 303 \\
\hline 860 & 350 & 200 & 18 & 540 \\
\hline
\end{tabular}

Table 1: Measured magnitude of intrinsic bending for several magnetic flaps.

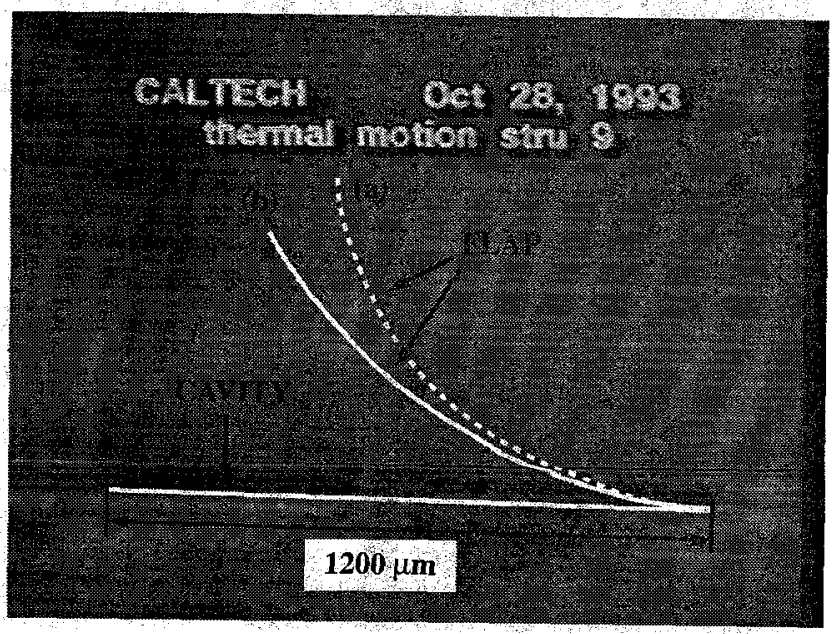

Fig. 7: Superimposed side profiles of the flap as grabbed from video images showing the flap positions (a) before; and (b) after applying $30 \mathrm{~mA}$ coil current. The flap is $860 \times 250 \mu \mathrm{m}^{2}$, the two cantilever beams are $280 \mu \mathrm{m}$ long and $24 \mu \mathrm{m}$ wide. 
those of gold. Using thermal coefficients of expansion of gold as $14.2 \times 10^{-6} /{ }^{\circ} \mathrm{C}$ [24] and of silicon nitride/polysilicon as $2.8 \times 10^{-6} /{ }^{\circ} \mathrm{C}[25]$, we obtain a temperature of roughly $300{ }^{\circ} \mathrm{C}$ for the above mentioned plate.

We have studied the frequency response of thermal actuation of our device by driving several devices with a square wave of current (50mA 0-peak). A typical spectrum is plotted in Fig. 8 for a flap $300 \times 300 \mu \mathrm{m}^{2}$ with cantilever beams each $200 \mu \mathrm{m}$ long and $18 \mu \mathrm{m}$ wide; it clearly shows a band-width of about $1 \mathrm{kHz}$. An ANSYS simulation of the same structure used in testing also showed the 1st mode resonant frequency to be at about $1 \mathrm{kHz}$. In addition, two smaller resonant peaks were experimentally observed - one at $180 \mathrm{~Hz}$ and another at $360 \mathrm{~Hz}$. These resonances also exist in several other flaps tested. The band-width is further verified by illuminating the vibrating flap with a stroboscope, which allows for more accurate measurement of vibration magnitude at higher frequencies. We were also able to use the stroboscope to accurately measure the thermal time constant. Different time constants, $.477 \mathrm{~ms}$ for heating and $.26 \mathrm{~ms}$ for cooling(forced convection), have been observed for this particular device.

In order to separate the thermal from the magnetic motion, we first pass DC current through the coil and observe the thermal motion of the flap. After the plate has reached thermal equilibrium and stays still, the magnetic field is applied by turning on the electro-magnet.

\section{Magnetic Motion}

Both permanent and electromagnets have been used to provide a magnetic field under the flap coil that is biased with DC currents ranging from 0 to $50 \mathrm{~mA}$. The electromagnet has a variable magnetic field with peak value of $1.76 \mathrm{kGauss}$ at $2.5 \mathrm{~A}$ current input; the permanent magnet gives a constant magnetic flux density of 2.8 kGauss measured at the magnet's surface. The $\vec{B}$ calibration for the electromagnet is shown in Fig. 9 and the gradient of $\vec{B}$ near the flap is about $280 \mathrm{Gauss} / \mathrm{cm}$. Under a $1.4 \mathrm{kG}$ magnetic flux density and a $40 \mathrm{~mA}$ coil current $(70 \mathrm{~mW})$ flowing through 3 turns of coil, a typical plate of $420 \times 420 \mu \mathrm{m}^{2}$ in size and suspended on one side by two cantilever beams ( $280 \mu \mathrm{m}$ long and $20 \mu \mathrm{m}$ wide) can achieve approximately $\pm 100 \mu \mathrm{m}$ DC vertical deflection. The grabbed video image of magnetic motion side profile of another flap is shown in Fig. 10 as an example.

We can use equation (1) and ANSYS finite element simulations to compare theoretical results with experimental. Using the same current and number of turns mentioned above together with our calibrated B-field gradient near the flap, we obtain a theoretical force of approximately $2.9 \mu \mathrm{N}$. Inserting this value of force into an ANSYS model results in a simulated deflection of over $100 \mu \mathrm{m}$.
We were not able to pass large (about 2.5 A) AC current with high frequency (up to $1 \mathrm{kHz}$ ) to the electromagnet because of the self-induction current in the electromagnet, so the frequency response of the magnetic motion is not available at the moment.

\section{Wind Tunnel Testing}

The full operation of the magnetic flap has not been tested in a wind tunnel yet, except for damage test to determine the maximum wind speed tolerance of the flaps. The flaps with two cantilever supports on one side are put in the laminar flow region of the wind tunnel and their breakage was monitored by a video camera. A typical flap will survival $50 \mathrm{~m} / \mathrm{s}$ airflow, which is the limit of the test wind tunnel, when the coil side of the flap faces the wind; the flap will fold over by $180^{\circ}$ and break at about $20 \mathrm{~m} / \mathrm{s}$ when the air flows in the opposite direction. Extensive studies of the flap behavior in a wind tunnel are underway.

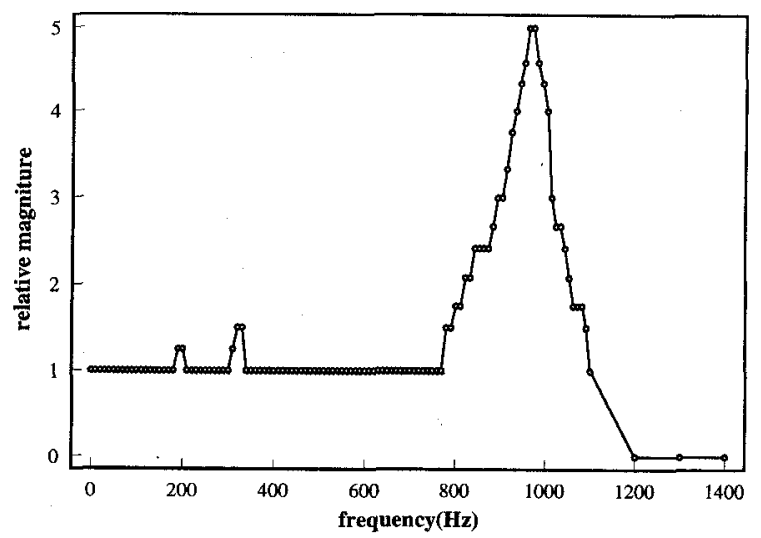

Fig. 8: Experimental frequency response of thermal actuation for a structure with a $300 \times 300 \mu \mathrm{m}^{2}$ flap and two cantilever beams, each $200 \mu \mathrm{m}$ long and $18 \mu \mathrm{m}$ wide. The resonant peak at about $1 \mathrm{kHz}$ correspondes to the first mode natural frequency of the flap.

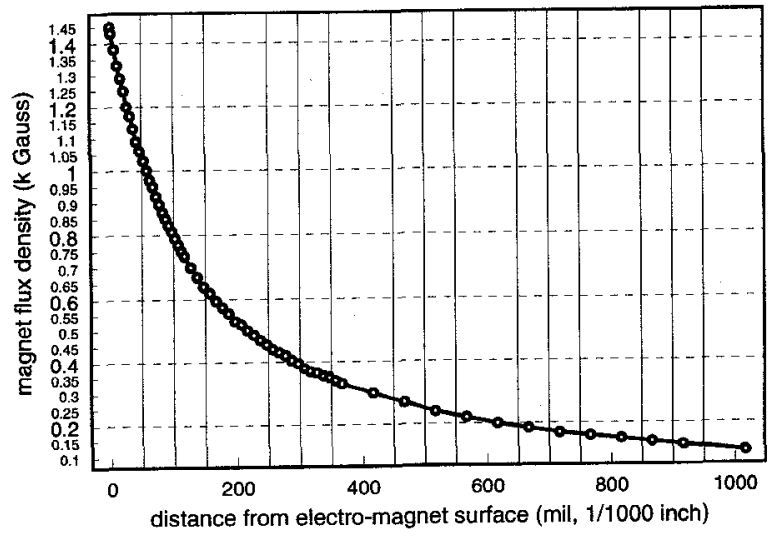

Fig.9: Calibrated magnetic flux density distribution along the axis of the electro-magnet core. The coil is located approximated $40 \mathrm{mil}$, or $1 \mathrm{~mm}$ away from the magnet surface, where is $\vec{B}$ gradient is almost constant. 


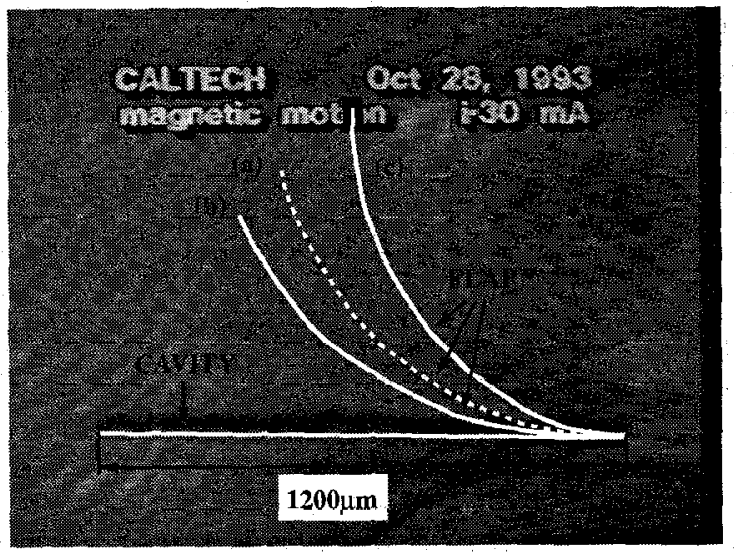

Fig. 10: Superimposed side profiles of the magnetic fiap as grabbed from video images showing the flap position (a) before applying magnetic field; (b)after being moved downward by a $B$ of approximately 1.7 kGauss; and (c) after being moved upward by a B of $1.7 \mathrm{kGauss}$. The flap is the same size as the flap in Fig. 7 and the coil current is $30 \mathrm{~mA}$.

\section{CONCLUSIONS}

A new type of surface-micromachined electromagnetic actuator with moving coils has been developed. Under a given magnetic field and magnetic coil current, the micro flap has a vertical deflection larger than $100 \mu \mathrm{m}$, a resonant frequency of $1 \mathrm{kHz}$, and an applied magnetic force of approximately $1 \mu \mathrm{N}$. We believe that these attributes can be further improved to meet the design specifications for the URI project. The magnitude of the thermal deflection by plate heating is comparable to that of the magnetic motion because of the large resistance from polysilicon plate; the problem of thermal actuation can be solved by reducing the resistance of the coil path to reduce heat generation. The intrinsic bending, however, needs to be neutralized by designing laminated layers that have zero combined stress.

\section{ACKNOWLEDGEMENT}

The authors thank Mr. Trevor Roper of the Caltech Micromachining Laboratory for maintaining processing equipment. This project is supported by the University Research Initiative (URI), a DOD/AFOSR joint project.

\section{REFERENCES}

1. I.J. Busch-Vishniac, "The case for magnetically driven microactuators", Sensors and Actuators, A33, pp. 207-220, 1992.

2. M.C.Jeong and I.Busch-Vishniac, "A submicron a.ccuracy magnetic levitation micromachine with endpoint detection", Sensors and Actuators, A29, pp. 225-234, 1991.

3. B. Wagner, W. Benecke, G. Engelmann and J. Simon, "Microactuators with moving magnets for linear, torsional or mutiaxial Motion", Sensors and Actuators, A32, pp. 598603, 1992.

4. K. Yanagisawa, A. Tago, T. Ohkubo and H. Kuwano, "Magnetic micro actuator", Proceedings of IEEE Micro ELectro Mechanical Systems, Nara, Japan, pp. 120-124, 1990.

5. D. Bosch, et. al., "A silicon microvalve with combined electromagnetic/electrostatic actuation", Sensors and Actuators, A37-38, pp. 684-692, 1993.

6. F. Cardot, et. al., "Microfabrication of high-density ar- rays of microelectromagnets with on-chip electronics", The 7th International Conference on Solid-State Sensors and Actuators, Transducer'91, pp.32-35, 1993.

7. H. Guckel, K.J. Skrobis, et. al., "Fabrication and testing of the planar magnetic micromotor", Journal of Micromechanics and Microengineering, Vol. 1, no. 4, pp. 135-138, 1991.

8. C. Ahn, Y. Kim and M. Allen, "A planar variable reluctance magnetic micromotor with fully integrated stator and wrapped Coils", Proceedings of the IEEE Micro Electro Mechanical Systems, pp. 1-6. 1993.

9. F. Cardot, F. Perret and H. Tannenberger, "Alloy electrodeposition of magnetic microstructures", 42nd Meeting of International Society of Electrochemistry, Montreux, Switzerland, 1991.

10. H.B. Dwight, Electrical coils and conductors, McGrawHill, 1945.

11. W.C. Young, Roark's formulas for stress and strain, 6th ed., McGraw-Hill,1989.

12. S. Timoshenko, "Analysis of bi-metal thermostats", Jour nal O.S.A and R.S.I 11, pp. 233-255, Sept., 1925.

13. M. Ataka, A. Omodaka and H. Fujita, "A biomimetic micro motion system - a ciliary motion system", Technical Digest of Transducers' '93, pp. 38-41. 1993.

14. W. Riethmuller and W. Benecke, "Thermally excited silicon microstructures", IEEE Transaction on Electron Devices, Vol.35, No.6, pp. 758-763, 1988.

15. W.C. Tang, T.C. Nguyen and R.T. Howe, "Laterally driven polysilicon resonant microstructures", Sensors and Actuators, 20, pp. 25-32, 1989.

16. Olin Hunt Specialty Products, Inc., Pad Etchant type 777.

17. G.T. Mulhern, D.S.Soane, and R. Howe, "Supercritical carbon dioxide drying of microstructures", Technical Digest of Transducers '93, pp. 296 298, 1993.

18. C.Mastrangelo and G.Saloka, "A dry release method based on polymer columns for microstructure fabrication", IEEE Micro Electro Mechanical Systems Workshop, Fort Laud erdale, Florida, USA,pp. 77-81, 1992.

19. R.L.Alley, G.J.Cuan, R.T.Howe and K.Komvopoulos, "The effect of release-etch processing on surface microstructure stiction", IEEE Solid-state Sensor and Actuator Workshop, Hilton Head Island, South Carolina, USA, pp. 202-207, 1992.

20. T. Hirano, T. Furuhata and H.Fujita, "Dry releasing of electroplated rotational and overhanging structures", $I E E E$ Micro Electro Mechanical Systems Workshop, Fort Lauderdale, Florida, USA, pp. 278-283, 1992.

21. M. Sekimoto, H. Yoshihara and T. Ohkubo, "Silicon nitride single-layer X-ray mask", J. Vac. Sci. Tech., vol.21, p. $1017 ; 1982$.

22. P. Krulevitch, R.T. Howe, G.C. Johnson and J. Huang, "Stress in undoped LPCVD polycrystalline silicon", 6th International Conference on Sensors and Actuators, Transducer '91', p. 949, 1991.

23. P.L. Castro, J.F.Campbell, "Stresses in thin films of aluminum", Ohmic Contacts to Semiconductors, Electrochemical Society, Inc., 1968.

24. R.C. Weast, CRC Handbook of Chemistry and Physics 67th ed., CRC Press, 1988.

25. R.S. Muller and T.I. Kamins,

Device Electronics for Integrated Circuits, Wiley, 1977. 